\title{
Economia de comunhão no Brasil: a produção acadêmica em administração de 1991 a 2006*
}

\author{
Sergio Proença Leitão** \\ Renée Assayag Spinelli***
}

Sumário: 1. O movimento dos focolares e a economia de comunhão; 2. Visão geral da produção e suas fontes; 3 . O conhecimento procurado; 4. Considerações finais.

Summary: 1 . The focolare movement and the communion economy; 2. General view of the production and its sources; 3 . The knowledge searched; 4. Last considerations.

Palavras-chave: movimento focolare; economia de comunhão; espiritualidade na gestão.

KEY WORDs: focolare movement; communion economy; spirituality in the management.

Este artigo, resultado de uma pesquisa bibliográfica, avalia a produção acadêmica em administração pública e de empresas, no Brasil, nos 15 anos de existência do Projeto de economia de comunhão. Observa que esta produção está concentrada, aqui e no exterior, em dissertações e teses, mas com temática dispersa. E discute visões teóricas e práticas que emergem dessa produção em crescimento contínuo.

Communion economy in Brazil: the academic production in administration from 1991 to 2006

This article results from a bibliographic research and evaluates the academic production about public and business administration in Brazil, in the 15 years of existence of the communion economy project. This production is concentrated, here and abroad, in dissertations and theses, but with diversified subjects. And discusses practical and theoretical visions that emerge from this ever-growing production.

\footnotetext{
* Artigo recebido em ago. 2007 e aceito em fev. 2008.

** Professor associado da Escola de Negócios da Pontifícia Universidade Católica do Rio de Janeiro (IAG/PUC-Rio). Endereço: Rua Marquês de São Vicente, 225 — Gávea - CEP 22453-900, Rio de Janeiro, RJ, Brasil. E-mail: spl@iag.puc-rio.br.

*** Doutoranda em administração do IAG/PUC-Rio. Endereço: Estrada da Gávea, 681, bl. 3, ap. 1604 - São Conrado — CEP 22617-010, Rio de Janeiro, RJ, Brasil. E-mail: renee.assayag@ simulation.com.br.
} 


\section{O movimento dos focolares e a economia de comunhão}

Como um projeto empresarial e econômico, a economia de comunhão (EdC) tem características particulares que a diferenciam de outras formas de economia solidária, pois nasceu de um movimento cristão, chamado movimento dos focolares, vinculado à Igreja Católica.

O movimento dos focolares (fogo no lar em italiano) surgiu das conversas da italiana Chiara Lubich com suas amigas, também jovens, reunidas em torno de uma fogueira no porão das ruínas de sua casa, em Trento, Itália, em 1943. Pensavam em um movimento capaz de levar à fraternidade universal, por meio da prática da espiritualidade da unidade entre os povos, para acabar com as guerras e a indigência no mundo. Ela e suas amigas - entre elas Ginetta Calliari, que viria também a ter importância no movimento -, ocupadas em socorrer as vítimas da guerra, formavam um grupo de jovens que procurava viver segundo o modelo das primeiras comunidades cristãs, com plena atenção para os mais necessitados. Concebia-se ali a construção de uma unidade (comunhão) com reflexos sobre o mundo econômico e do trabalho (Lima, 1999).

Para materializar esse ideal, o movimento começou a fundar pequenas comunidades em vários países - são hoje mais de 70 - chamadas "mariápolis", sendo que, no Brasil, a primeira dessas cidadelas foi instalada em Recife, em 1958. Essas cidades de Maria serviram inicialmente para centros de estudos e debates, transformando-se depois em pólos empresariais. O movimento dos focolares expandiu-se ao longo dos anos, foi reconhecido pelo papa João Paulo II e hoje conta com mais de 8,5 milhões de pessoas entre aderentes e simpatizantes, espalhados pelos cinco continentes.

Foi desse movimento que surgiu o projeto de economia de comunhão, sua versão empresarial-econômica, pois, segundo Lubich (2004:29), líder carismática do projeto, era preciso levar seus princípios a uma ação concreta e transformadora. Foi em algumas daquelas cidadelas que se instalaram os primeiros pólos industriais do projeto de EdC.

O projeto foi lançado no Brasil em maio de 1991, pela mesma Chiara Lubich, em Vargem Grande Paulista, São Paulo, onde está também seu escritório no Brasil: o escritório central fica na Itália. Nessa localidade foi criado o primeiro pólo brasileiro, em 1994, chamado Spartaco, que deveria funcionar como um laboratório para um novo estilo de gestão econômica, transparente, eficiente e responsável (Bruni, 2002). O pólo tornou-se conhecido e já recebeu visitas de empresários, políticos e pesquisadores do Brasil e do exterior de mais de 50 países, curiosos em conhecer os resultados dessa nova experiência 
em economia social, que teve outros experimentos de maior ou menor sucesso, durante os séculos XIX e XX, como os movimentos cooperativos quakers e as friendly societies (Linard, 2003).

Para viabilizar esse pólo empresarial foi criada uma empresa sob a forma de sociedade anônima, cuja função era criar a infra-estrutura necessária ao projeto, a Espri S.A. Empreendimentos, Serviços e Projetos Industriais, arrecadando fundos por meio de lançamento de ações — hoje perto de 4 mil acionistas - e administrar os serviços comuns do pólo (Pinto e Leitão, 2006:20).

Operando em mercados locais, essas empresas têm sua capacidade de expansão mundial apoiada por uma rede de comunicação dos focolarinos, capaz de aumentar globalmente o ideário do projeto (Linard, 2003), como também pela liberdade usufruída pelos empresários de EdC na condução de suas empresas. Em fins de 2006, nos cinco continentes, havia mais de 820 empresas, a grande maioria com até 50 funcionários. A Itália é o país com mais empresas registradas no projeto e com maior produção acadêmica sobre ele, seguida do Brasil. No período 1991-2005 as empresas registradas ao projeto de EdC cresceram no mundo a uma taxa anual líquida de 13\% e, no Brasil, de $7 \%$. O projeto obteve reconhecimento internacional através da Unesco e do Conselho da Europa, tendo Chiara Lubich recebido títulos honorários em prestigiadas universidades (Linard, 2003).

Bruni (2005:25), um dos economistas italianos que mais estudaram esse projeto, diz que a economia de comunhão busca uma nova relação entre mercado e sociedade ao desafiar as ideologias dominantes na era da globalização. São empresas privadas, inseridas no mercado, que salvaguardam a propriedade particular dos bens, colocando o lucro em comunhão: uma visão humanista cristã do mundo dos negócios. Dizem Pinto e Leitão (2006:139) que, nelas, o diferente está na forma como as pessoas tratam umas às outras, incluindo os clientes, os fornecedores e os demais stakeholders. O grande diferencial estaria na qualidade dos seus relacionamentos interpessoais e inter-organizacionais. Embora seja também possível destacar as redes de contato comercial que elas formam, criando, inclusive, uma zona de amortecimento de choques para suportar pressões do mercado.

O conjunto de estudos aqui examinado não mostra referências teóricas específicas à economia de comunhão, porque não existe uma "teoria de EdC". Mostra as práticas adotadas por essas empresas e, por vezes, vinculações com as teorias organizacionais conhecidas. São em grande número, estudos exploratórios, pois não é usual o conhecimento das relações operacionais e estratégicas entre espiritualidade, como motivação para o trabalho, e gestão de negócios. 
São, portanto, empresas que se constituíram ou se adaptaram, para adotar os princípios espirituais cristãos, contidos nos evangelhos e na doutrina social da Igreja, no âmbito dos negócios. Chiara Lubich não tinha em mente, ao idealizar o projeto, uma construção teórica, seja em economia ou administração, mas procurava uma resposta concreta a uma necessidade real da sociedade mundial (Lubich, 2004:28). Quando percebeu que o projeto se tornara uma realidade, começando, inclusive, a ser integrado por empresários não-religiosos ou de outras religiões, ela passou a convocar a comunidade acadêmica para estudá-lo.

A resposta a esse apelo não veio, a não ser marginalmente, de pesquisadores acadêmicos experientes, desconfiados, talvez, dessa intimidade entre religião e negócios, mas de mestrandos, doutorandos, ou mesmo graduandos, em diversas áreas de conhecimento e diversas universidades espalhadas pelo mundo. Foi o lado jovem da academia e professores-orientadores curiosos, apoiados em seus alunos, que atenderam àquela proposta.

No Brasil, ela também foi recebida com desconfiança pelos professores da corrente dominante, particularmente na área de administração, provavelmente porque se trata, em sua maioria, de pequenas empresas, em uma cultura acadêmica americanizada, que valoriza a grande corporação. Também aqui a questão da espiritualidade pesou: um artigo enviado a uma revista acadêmica, em 2001, foi recusado por ter o avaliador considerado a empresa estudada fruto da imaginação do autor.

Almeida e Leitão (2003) acreditam ter sido o potencial transformador das formas de gestão e da vida associada, embutido nesse projeto, que despertou o interesse da comunidade acadêmica, particularmente dos estudantes, mais voltados para alternativas à velha opção capitalismo versus socialismo, ou a uma economia de grandes corporações. A grande ambição do projeto de economia de comunhão - transformar as empresas para mudar a economia e a sociedade humana - justificaria a curiosidade dos não-céticos quanto à possibilidade de um novo caminho para um planeta socioambientalmente sustentável.

Tal quadro justifica a absoluta dominância de dissertações e teses no meio acadêmico sobre o projeto de EdC, onde são raros os artigos baseados em pesquisa empírica ou ensaios, salvo os que reproduzem tais teses e dissertações. A produção de membros do meio acadêmico mais experientes está limitada a livros com coletânea de artigos, publicados por uma editora pertencente ao projeto.

A finalidade deste artigo, baseado em pesquisa bibliográfica, é avaliar os resultados da produção acadêmica, basicamente em termos de dissertações 
de mestrado e teses de doutorado, no período 1991-2006, mais atento ao caso brasileiro. E também discutir, de forma introdutória, os interesses teóricos e práticos que emergem dessa produção, mas sem explorar em mais detalhe as epistemologias ou paradigmas que a orienta.

\section{Visão geral da produção e suas fontes}

Os apelos de Chiara Lubich alcançaram os pós-graduandos e alguns graduandos de 26 países, dos quais 15 europeus (148 estudos), seis sul-americanos (138 estudos), três africanos (três estudos), além de uma contribuição das Filipinas e outra da Coréia do Sul, no período de 2001 a 2006. Foram 291 trabalhos aprovados em universidades, conforme o banco de dados do escritório de EdC, na Itália, no site <www.tesi.ecodicom.net/>. Embora sejam dados provavelmente incompletos, pois o envio da informação a esse banco de dados é freqüentemente de iniciativa dos autores, o que nem sempre ocorre, pelo menos de forma atualizada. Pode-se tomar esse número como piso da produção acadêmica no período, pois certamente ele é maior.

No total da produção ali registrada, a Itália é o país com maior número de trabalhos aprovados (127), seguida do Brasil (122), e muito atrás, em terceiro lugar, a Argentina com cinco estudos. A maior parte dos países europeus se faz ali representar, incluindo principados como Luxemburgo ou a ilha de Malta, mas nessa estatística não há registro de estudos produzidos no continente norte-americano, sugerindo pouco interesse por essa linha de investigação alternativa, particularmente no país de maior produção acadêmica do planeta. Talvez isso também explique a falta de interesse dos pesquisadores brasileiros para o tema, pois nas revistas americanas de administração está sua maior fonte de referência para pesquisa.

No Brasil, os 122 trabalhos foram aprovados em 43 instituições de ensino superior. E o interesse despertado não demonstra clara relação com instituições de ensino confessionais, pois 18 foram apresentados em 16 universidades federais - dos quais cinco na Universidade Federal do Rio Grande do Norte - e 13 aprovados em quatro PUCs (Pontifícia Universidade Católica). O número restante de escolas confessionais é irrelevante.

Por outro lado, é significativo o número de universidades estaduais, seguidas, em menor número, de instituições privadas leigas e por fundações. Porém, a instituição com maior número de trabalhos (6) é a PUC-Rio, abrangendo quatro dissertações e duas teses, além de oito artigos acadêmicos publicados, em parte baseados naquelas dissertações e teses. Os dados institu- 
cionais mostram, portanto, considerável diversificação, no segundo país com maior produção acadêmica sobre economia de comunhão.

O exame das áreas de conhecimento exploradas por esses estudos, em nível mundial, apresenta as seguintes áreas em ordem decrescente de volume de produção: economia (principalmente microeconomia); administração; filosofia (incluindo ética e axiologia); teologia; sociologia (principalmente sociologia das organizações); direito; psicologia do trabalho e psicologia social; gestão ambiental; antropologia; história; serviço social; geografia econômica e geografia política.

No âmbito da administração de empresas, os temas abordados, também em ordem decrescente de trabalhos aprovados, são os seguintes: características gerais do projeto e modelagem; cultura organizacional; gestão de pessoas; relacionamentos interpessoais e interorganizacionais; sustentabilidade; gestão participativa; ética na gestão; informação e comunicação empresarial; teoria dos stakeholders; responsabilidade social corporativa; gestão contábilfinanceira; racionalidade e gestão; qualidade de vida no trabalho; estratégia empresarial; motivação; aprendizagem organizacional; controle gerencial; controle de qualidade; mudança organizacional; marketing de serviços; gestão de turismo; consultoria; teoria de EdC.

No caso brasileiro, os estudos no âmbito da administração de empresas, têm a seguinte ordem decrescente de importância: características gerais do projeto e modelagem; estratégia empresarial; gestão contábil-financeira; gestão participativa; cultura organizacional; racionalidade e gestão; humanização da gestão (gestão de pessoas); sustentabilidade; qualidade de vida no trabalho (gestão de pessoas); relacionamentos interpessoais e interorganizacionais; ética na gestão; responsabilidade social corporativa; aprendizagem organizacional; subjetividade e gênero (gestão de pessoas); teoria dos stakeholders; informação e comunicação empresarial; gestão de turismo; marketing de serviços; consultoria; teoria de EdC.

Existe, portanto, considerável diversificação temática, com alguma concentração em estudos que procuram uma descrição geral e modelagem do projeto e os relativos a gestão de pessoas, considerada por muitos autores como seu grande diferencial, observando-se que a qualidade dos relacionamentos interpessoais também aí se insere.

Há ainda evidências, como também observou Linard (2003), de que esses estudos de pós-graduação e os artigos sobre pesquisas empíricas ou ensaios estão em expansão, ante a crescente curiosidade despertada pelo projeto de EdC nos últimos anos. 
No momento, grande parte dessas pesquisas se baseia em estudos de caso simples e múltiplos, com metodologias qualitativas ou combinadas. A possibilidade de aprofundar a ambiência dessas organizações e a busca de conhecimento mais conceitual justificaria essa preferência pelo estudo de caso.

Do ponto de vista epistemológico, a presença da visão funcionalista é notada, embora abordagens interpretativistas, nos termos da conhecida tipologia de Burrel e Morgan (1979) estejam também presentes. Há um único caso de abordagem marxista, registrado (Wellen, 2004).

Um primeiro exame dessa produção sugere uma vocação para uma visão subjetivista, que busca interpretar o simbolismo dos princípios cristãos na práxis das empresas do projeto. Também se observa uma ampliação da consciência dos empresários que transcende a instrumentalidade e o individualismo tradicionais nas ações empresariais. É possível notar nos depoimentos dos que dirigem as empresas mais avançadas do projeto, a clara intenção de construir uma nova ordem empresarial e econômica, atribuindo um novo conjunto de significados à gestão dos negócios. E isso favorece as visões interpretativistas e humanistas do universo organizacional da economia de comunhão.

Na realidade, os estudos sobre EdC retomam as discussões sobre as limitações das visões paradigmáticas e a fragilidade da corrente funcionalista, hegemônica, para explicar sozinha o que é economia de comunhão. Os textos aqui examinados estão sugerindo uma visão mais ampla do que seja religião e espiritualidade e sua presença possível na pesquisa em administração. Essa integração do sacro com o secular, na busca de mais autodeterminação e liberdade, lembra a questão axiológica posta por Lincoln e Guba (2000:163) sobre a possível aproximação entre as visões construtivista e participativa. Esta, particularmente preocupada com o possível balanceamento entre autonomia, cooperação e hierarquia, que no caso EdC, se desenvolve em tipo de cultura preocupada com a partilha. $\mathrm{O}$ que já foi produzido sobre esse projeto sugere $\mathrm{o}$ caminho do pluralismo, a permissão para abordagens múltiplas e não o favorecimento de um só domínio de saber.

A maior parte dessas dissertações e teses focalizou empresas que aderiram ao projeto desde seu início, consideradas na vanguarda do projeto, pois o progresso dessas empresas quanto à implantação do ideário disseminado por Chiara Lubich e sua principal auxiliar, Ginetta Calliari, é desigual (Almeida e Leitão, 2003). Por esse motivo, empresas como a Femaq, Prodiet, Policlínica Ágape ou a La Túnica são recorrentes em diversos estudos.

No âmbito dos artigos e livros acadêmicos, no Brasil, há muito pouco a registrar. A maior parte dos textos publicados está em livros tipo coletânea, editados pela Editora Cidade Nova, vinculada ao projeto EdC. Nela vem sendo 
publicada a maior parte dos ensaios sobre o projeto, dominando temas econômicos, filosófico-religiosos e sociológicos. A maioria dos articulistas é de origem italiana, que acompanham o projeto desde sua criação e mantêm estreita vinculação com ele: um dos raros autores brasileiros presentes é a socióloga Vera Araújo, com significativa produção sobre EdC. Ali são encontradas visões impressionistas do projeto, análises fenomenológicas e perspectivas teóricas; a pesquisa empírica está praticamente ausente nessas coletâneas.

Provavelmente, o primeiro artigo acadêmico no Brasil, no âmbito da administração de empresas, foi publicado por Lima em novembro de 1999. E o primeiro livro baseado em pesquisa empírica (tese de doutorado) foi publicado por Pinto e Leitão (2006), editado pela Fundação Getulio Vargas do Rio de Janeiro.

Dissertações e teses, além de monografias, constituem, portanto a maior contribuição da academia ao conhecimento do projeto, no presente momento. E o exame de alguns desses estudos pode mostrar por quais aspectos transitou a curiosidade desses estudantes sobre a economia de comunhão, enfatizando-se os temas que foram considerados diferenciadores das empresas desse projeto.

\section{0 conhecimento procurado}

O primeiro e natural impulso desses estudantes-pesquisadores e seus orientadores, e dos primeiros articulistas, foi conhecer características gerais dessas empresas, ou tentar descrevê-las por meio de modelagem, em busca de suas peculiaridades. Na segunda metade dos anos 1990 ainda era grande o desconhecimento do projeto na universidade.

O artigo de Gonçalves e Leitão (2001), o primeiro publicado no eixo Rio-São Paulo, é exemplo de um estudo de caso exploratório, extraído dos primeiros levantamentos de campo da pesquisa de tese de Gonçalves (2005), que oferece uma perspectiva geral do projeto e as peculiaridades da empresa estudada. $\mathrm{O}$ artigo concluiu que a política de pessoal dessa empresa possibilitava elevada produtividade e que o projeto tinha vínculos conceituais com mudanças de natureza transformadora no meio empresarial. E sugeriu 12 questões que deveriam ser objeto de futuras pesquisas. Foi o primeiro a mostrar a preocupação dessas empresas com a questão ambiental, relatando o aproveitamento da areia poluída na fundição Femaq.

A tese de Gonçalves (2005) iria explorar os valores declarados e os praticados nessas empresas, ao sistematizar e avaliar qualitativamente as experi- 
ências das empresas do projeto nos seus 10 primeiros anos. Ela mostra avanços, tensões, contradições e limites da inovação proposta por Chiara Lubich, observando que havia um longo caminho de aprendizagem a ser percorrido naquela forma mais humanizada de organização de trabalho.

Já a preocupação de Lima (1999) foi mais específica: utilizar a teoria dos custos de transação para confrontá-la com as práticas econômico-financeiras daquelas empresas. Ela observa que a proposta trazida pelo projeto EdC não encontra suporte naquela teoria que pressupõe, entre outras coisas, a atuação de indivíduos e empresas na busca de minimização dos custos relacionais a partir da regulação por contratos. Nas empresas de EdC, todavia, as relações são baseadas na confiança mútua, independentemente dos contratos, desenvolvendo uma cultura organizacional fundada no diálogo e na qualidade dos relacionamentos interpessoais. Seu argumento de que nessas empresas os custos de transação tendem a ser menores coincide com os do economista italiano Stefano Zamagni (2002:11) quando este afirma serem os custos de transação, monitoração e de confiança mais baixos nessas empresas do que nas outras.

A tese de doutoramento de Brandalise (2003) deteve-se em analisar as limitações legais para a contabilidade dessas empresas, particularmente quanto a contabilização da parte do lucro destinada ao fundo para a pobreza, gerido internacionalmente, com o objetivo de apoiar projetos (a fundo perdido) em populações carentes. Mas em suas conclusões constatou a estabilidade das empresas estudadas, quanto a faturamento e lucro, se comparadas a outras fora do projeto.

A viabilidade econômico-financeira dessas empresas, substantivamente orientadas, preocupadas com a partilha das decisões e dos resultados, constituiu uma preocupação imediata dos primeiros a tomar conhecimento do projeto. O estudo de Brandalise (2003), quanto à viabilidade do projeto EdC, encontrou apoio no exterior, na tese de Merla (2003), de conclusão similar quanto à viabilidade e a sustentabilidade da economia de comunhão. E manteve afinidade com o estudo anterior, no Brasil, de Nascimento (1999), preocupado com a produtividade e a humanização do lucro nessas empresas.

A importância específica do lucro nas empresas de EdC e de sua viabilidade voltaria a ser a preocupação de Lima Jr. em seu estudo de 2006, como o fora em Vido (2004), destacando este o papel de uma cultura organizacional que valoriza o ser humano como indivíduo e ser social, chamado no âmbito do projeto de "cultura do dar" ou de "cultura da partilha".

A questão da sustentabilidade, envolvendo o crescimento contínuo e harmonioso com o meio ambiente é parte relevante no ideário de EdC e foi ob- 
jeto de investigação de Gameleira (2000), Santana (2003) e Bartholo (2003). A preocupação com produtos de qualidade que não agridam o meio ambiente está presente nas estratégias empresariais dessas empresas. E Santana (2003), em sua dissertação, sugere um modelo de gestão ambiental enfocando tecnologias acopladas à filosofia da economia de comunhão, para implantação em empresas do semi-árido sergipano, por meio de cinco procedimentos básicos.

Bartholo, por sua vez, examinou aspectos teóricos e práticos das empresas de EdC, considerando sua importância para o desenvolvimento sustentável, particularmente quanto à geração de emprego e renda em comunidades pobres. Enquanto Gameleira (2000) havia sugerido que os pressupostos de EdC fossem aplicados à cultura canavieira, para transformar padrões insustentáveis como os vigentes na Zona da Mata.

Vinculada também à questão da cultura, a qualidade dos "relacionamentos" surge como o maior valor praticado naquelas empresas, não se restringindo às trocas, mas representando o encontro de pessoas que os vivenciam, sem instrumentalizá-los, sem usá-los como simples meio, visualizando-os de forma substantiva. Almeida (2002) já havia percebido a importância desse fator quando buscou a presença da razão substantiva em três empresas do projeto, vinculando-a com a qualidade dos relacionamentos interpessoais ali praticados. Esse autor também percebeu, nesse estudo, que o progresso dessas empresas para alcançar o ideário de EdC, elaborado por Chiara Lubich, se fazia de forma desigual, o que é inerente à ênfase na liberdade (de buscar o caminho para a cultura da partilha) que ela e os demais idealizadores do projeto lhe dão.

Também Barros (2004) vê a potencialidade da economia de comunhão para amenizar o sofrimento psíquico no trabalho, a partir de seu modo de gestão e da sua cultura, considerando, em uma perspectiva psicológica, mais adequados às necessidades humanas seja no trabalho, seja na vida como um todo.

A ênfase nos relacionamentos, sobretudo os pessoais, aparece em diversos outros estudos. São exemplos o de Fortes (2004), focando valores, e o de Mendes (2003), que analisou seis empresas do pólo empresarial Spartaco, em São Paulo, para concluir que o nível de satisfação dos empregados nos seus contatos pessoais é muito superior ao de empresas similares fora do projeto. Mas, nesse tema, talvez o estudo mais incisivo seja a tese de doutoramento de Pinto (2004), apontando a qualidade dos relacionamentos interpessoais e interorganizacionais como o grande diferencial competitivo dessas empresas. Ele utilizou a teoria dos stakeholders e o movimento da responsabilidade social corporativa (RSC), como fontes de sua análise, encontrando peculiaridades em EdC que não podem ser plenamente explicadas naquelas óticas interligadas. 
Em linha próxima, Dallabrida (2004), preocupado com a sustentabilidade, realizou um estudo comparativo entre uma empresa de EdC e outra pertencente ao movimento de RSC, para avaliar o discurso e a prática nas formas de gestão adotadas, concluindo que as duas práticas podem fornecer mais equilíbrio do que a visão utilitarista dominante. Silveira (2003), em seu estudo de caso, também havia encontrado afinidades entre as práticas de EdC e a concepção de RSC.

Mas a questão da qualidade dos relacionamentos em EdC, identificada como elemento central na "cultura da partilha" pelos autores italianos vinculados ao projeto, tem implicações para as diversas áreas da administração dessas empresas. E isso acaba por tornar o tema relacionamentos o mais presente nos estudos sobre EdC, apesar de não explicitado no título das diversas teses e dissertações aprovadas.

O estudo de Kurtz (2005) sugere que a qualidade dos relacionamentos em uma das empresas líderes do projeto é um facilitador da aprendizagem de tarefas e de comportamentos na empresa estudada, com implicações para a mudança organizacional e a forma como ali se trata o conhecimento. O estudo aponta a existência de uma aprendizagem coletiva espontânea em uma empresa onde a direção desconhecia os conceitos de aprendizagem organizacional e de organização de aprendizagem. E observa que a meta comum às empresas do projeto EdC, de formação de um "homem novo", ou seja, uma nova mentalidade entre dirigentes e trabalhadores acaba por levar a empresa a um processo de aprendizado constante, relacionado ao contexto da organização, com repercussão em suas práticas operacionais e estratégicas.

Dando continuidade ao estudo de Kurtz, a dissertação de Sampaio (2006) examinou a mesma empresa e outras três, no pólo Spartaco, quanto a suas compatibilidades com 14 características consideradas típicas de uma organização de aprendizagem, extraídas de 23 autores que ajudaram a construir o conceito de organização de aprendizagem apresentado no estudo de Carvalho (1999). A análise estatística e a de conteúdo mostraram grande afinidade das práticas adotadas com aquelas características, segundo a percepção dos diretores e funcionários das quatro empresas analisadas.

A presença da qualidade dos relacionamentos, que alguns diretores de empresas de EdC, chamam de ênfase no diálogo, está presente ainda em outros trabalhos com diferentes objetos de estudo, como na tese de Machado (2006). Esse é um raro exemplo de estudo teórico sobre economia de comunhão que, depois de examinar os diversos temas abordados nos estudos organizacionais de orientação dominantemente funcionalista, instrumental e também materialista, aponta sua insensibilidade para a explicação (objetivis- 
ta) e compreensão (subjetivista) do fenômeno EdC. Sua proposição é de que uma teorização sobre esse projeto terá de considerar sua ontologia substantiva, fundada nos princípios da espiritualidade da unidade e do amor-comportamento, com epistemologia e metodologia pertinentes. Inclina-se, nesse sentido, para abordagens subjetivistas, capazes de interpretar o forte simbolismo do humanismo cristão embutido no ideário do projeto, cuja subjetividade penetra o transcendente.

Lembremos que o papel da organização econômica na visão de EdC, explícito nos textos de Lubich (2004) tem natureza transcendente. Embora não deixe isso explícito, o estudo de Machado (2006) se inclina para uma visão metaparadigmática, supondo um discurso construtivo e crítico nos termos de Alvesson e Deetz (1999:237).

Por outro lado, o exame dos artigos publicados, bem como estudos aqui examinados, parecem sugerir, como já observado, que o interpretativismo e o humanismo radical são as epistemologias pertinentes para descrever EdC. É possível perceber uma maior sensibilidade ao ideário do projeto nos estudos que trabalharam com métodos lingüísticos de orientação interpretativista, assim como a ótica humanista de alguns pode mostrar, com mais clareza, a disponibilidade das lideranças para a mudança. Tal análise, todavia, será objeto de outro estudo.

A qualidade dos relacionamentos, inspirada na visão transcendente da espiritualidade da unidade, como no conceito cristão de amor-comportamento, também tem implicações diretas na visão ética dos negócios nesse projeto empresarial e econômico. Tal fundamento iria motivar estudos focando a natureza ecumênica do projeto de EdC, como o de Spers (2004), ou aspectos filosóficos, como o de Ferreira (2004) ao analisar o carisma e a modernidade, sob a ótica de Max Weber, nas empresas de economia de comunhão.

Mas a dimensão ética tem aí prioridade, em face da natureza do projeto e da ênfase na "cultura da partilha". Ela aparece em diversos trabalhos, abordada sob diversos prismas. O estudo de Medaglia (2003), por exemplo, utiliza o ponto de vista jurídico para aprofundar a preocupação ética de uma empresa do projeto, ao colocar a pessoa no centro de seus objetivos empresariais. Lima (1999) já havia identificado EdC como um contraponto à economia consumista, à "economia do ter", como uma opção para a superação dos atuais impasses econômicos.

A relação entre a preocupação ética e o princípio da espiritualidade da unidade, integrante do movimento focolarino, foi apontada também por Serafim (2001). Sua dissertação procura demonstrar que a ética está presente na cultura EdC, devido a aspectos como: desenvolvimento de um espaço or- 
ganizacional alicerçado na consideração da multidimensionalidade humana, fator fundamental à gestão das pessoas; disseminação de práticas éticas pelos exemplos pessoais dos dirigentes; ações de gerência onde convergem a ética da responsabilidade e a ética da convicção, nos termos de Enriquez (1997).

Mais recentemente, Leite (2005) contribuiu para o entendimento das práticas éticas em economia de comunhão, ao analisar a constituição do projeto de EdC, procurando entender em que medida uma "economia do dar" poderia advir de uma cultura determinada por uma experiência coletiva: o movimento dos focolares. Aspecto que também Pinto (2005) considerou, ao avaliar a participação daquele movimento na continuidade do crescimento do projeto. Ética e substantividade no pensar e agir EdC foram temas presentes em Almeida (2003), quando utiliza o conhecido conceito de organização substantiva de Guerreiro Ramos em seu livro A nova ciência das organizações, para verificar se as três empresas estudadas podiam ser qualificadas como organizações substantivas.

\section{Considerações finais}

Os exemplos selecionados, para sumariar as preocupações mais presentes na produção acadêmica relativa aos 15 anos de existência do projeto EdC no Brasil, permite algumas conclusões iniciais sobre o perfil dessa produção.

A primeira é de que é um conjunto de estudos dispersos quanto aos temas focalizados, seguindo a curiosidade pessoal de cada pesquisador, o que, aliás, não é tão incomum nos estudos organizacionais. Salvo o caso do tema aprendizagem em Kurtz (2005) e Sampaio (2006) que, por sua vez, toma como base um estudo de Carvalho (1999), onde existe intenção explícita de investigar aprendizagem em EdC, sob a liderança de um mesmo professororientador, não se pode falar em desenvolvimento de linhas temáticas continuadas, dentro do conjunto de trabalhos sobre o projeto EdC. Diversos estudos mostram referências a estudos anteriores, embora a prioridade nessas citações esteja nos autores italianos das coletâneas editadas pela Cidade Nova, mas não propriamente na continuidade e aprofundamento de uma linha de investigação. Talvez a juventude do projeto seja uma explicação, por induzir a uma curiosidade multivariada.

Como observado, surgem temas recorrentes em estudos de objetivos diferentes. Os mais comuns são os relacionamentos interpessoais e a cultura organizacional, tratados por vezes de forma independente, e a visão ética, substantiva, do mundo dos negócios em EdC. Essa é, aliás, uma visão que 
abrange a crise ambiental e a sustentabilidade, porque é percebida pelos empresários de EdC como crise socioambiental, decorrente de como as sociedades humanas vêm tratando o ambiente natural. A visão contida no ideário de economia de comunhão é integrativa, relacional a múltiplos aspectos da vida associada.

Há também casos de temas recorrentes tratados de forma nem sempre explícita, como é o caso da mudança organizacional. Ela é intenção do projeto, mas foram poucos os estudos que a tomaram como objeto de investigação. Aparece em referências vinculadas a objetos como aprendizagem, ou a um dos objetivos do projeto EdC que é a formação de um homem novo: os outros dois são a partilha do lucro e o reinvestimento no próprio negócio. Ou é citada quando se discute EdC como uma terceira via e se critica as condições postas pelo capitalismo em sua forma atual. E, de um modo geral, não se costuma fazer diferenciação entre mudança adaptativa e mudança transformadora que é mais afim com o ideário de EdC, ante sua intenção de substituir o atual consumismo e utilitarismo por uma visão comunitária que organiza a produção e, principalmente, a distribuição do lucro.

No conjunto dos estudos examinados, se há clara preocupação em descobrir o diferente na gestão das pessoas, existem também temas ainda pouco explorados, ou esquecidos, como: cognição, liderança, motivação, poder, conflito, decisão, criatividade ou comunicação, temas clássicos nos estudos organizacionais. Ou ainda temas introduzidos pela corrente humanista, pouco presentes em nossos estudos organizacionais como linguagem, racismo, desejos e pulsões no trabalho, espaço pessoal, interioridade na gestão e outros. Provavelmente eles surgirão antes que uma linha temática possa ser considerada esgotada.

Por outro lado, os estudos já produzidos permitem perceber, independentemente do objetivo do estudo, que baixo nível de conflito, visão comunitária da empresa e maior sentido de pertencimento social são características muito presentes no conjunto das empresas do projeto que representam sua vanguarda. O que não está evidente é se isso tem maior vinculação com a presença dos focolarinos ou não.

Há também indícios que estimulam o estudo do emocional no trabalho, pois, como lembra a visão feminina de Oliveira (2003:58), nessas empresas ninguém toma "vacina contra vírus passionais". Também há estímulos ao estudo do tempo psicológico porque parece haver maior disponibilidade relativa dos funcionários para sua vida privada. Diversos temas ligados à dimensão humana não foram suficientemente explorados, temas que essas empresas parecem aptas a oferecer ao investigador organizacional, sobretudo quando 
lembramos que, apesar do grande progresso técnico, continuamos com dificuldades para conviver uns com os outros no trabalho.

Pode-se também perceber, mesmo quando se considera a produção mundial, que ainda está distante a formulação de uma teoria integrada de EdC, inclusive no campo específico a uma teoria organizacional de EdC. O primeiro esforço brasileiro de uma visão integrativa em organizações, feito por Machado (2006), ainda requer continuidade de investigação teórica e empírica.

Outra conclusão é que, paralelamente ao crescimento das empresas registradas no projeto EdC, há também um aumento no número de trabalhos acadêmicos. O tema começa a se fazer presente nos encontros da Anpad ou em seminários e simpósios realizados em universidades brasileiras.

Começam a surgir também os primeiros artigos de pesquisadores mais experientes, embora, na maioria dos casos, fora do Brasil. A presença de artigos acadêmicos sobre EdC é eventual nas revistas brasileiras e ainda está muito concentrada em uma revista do Rio de Janeiro.

O projeto de EdC surge, todavia, como um exemplo de humanismo cristão em desenvolvimento no âmbito das organizações produtoras, principalmente nas de pequeno e médio portes (Leitão e Lameira, 2005) e parece, no atual quadro de crise socioambiental, ter organização e motivação suficientes para vencer resistências na academia.

Se a universidade, particularmente em seus cursos de administração de empresas, tem sido muito mais uma instituição reprodutora de conhecimento do que uma formuladora de visões críticas e alternativas ao stablishment, a curiosidade dos pesquisadores pode acabar se voltando para o que há de novo nessas empresas inspiradas em princípios milenares, mas que parecem estar demonstrando sua viabilidade prática no mundo dos negócios, até então excludente à dimensão espiritual da vida. $\mathrm{O}$ que fica evidente nesse conjunto de estudos é que a realidade EdC, ali descrita, é algo academicamente instigante e isso incentiva a continuidade da pesquisa, seja ela tratada como um caso particular de gestão de empresas, ou como o início de uma nova forma capitalista de ser.

\section{Referências bibliográficas}

ALMEIDA, M. A. As empresas de economia de comunhão: possibilidade e valorização da racionalidade substantiva na organização econômica. 2002. Dissertação (Mestrado) - Departamento de Administração da Pontifícia Universidade Católica (PUC-Rio), Rio de Janeiro, 2002. 
; LEITÃO, S. P. Economia de comunhão e razão substantiva. Revista de Administração Pública, v. 37, n. 6, p. 1145-1170, nov./dez. 2003.

ALVESSON, M.; DEETZ, S. Teoria crítica e abordagens pós-modernas para estudos organizacionais. In: CLEGG, S.; HARDY, C.; NORD, W. (Orgs.). Handbook de estudos organizacionais. São Paulo: Atlas, 1999.

BARROS, W. M. Economia de comunhão: novos paradigmas propostos para a organização do trabalho. 2005. Dissertação (Mestrado) — Departamento de Psicologia da Universidade de Fortaleza, Ceará, 2005.

BARTHOLO, Fernando. Empresa de participação comunitária: aspectos teóricos e práticos. 2003. Dissertação (Mestrado em Administração) — Universidade Mackenzie, São Paulo, 2003.

BRANDALISE, L. A. A finalidade do lucro para as empresas de economia de comunhão. 2003. Tese (Doutorado) — Faculdade de Economia, Administração e Contabilidade da Universidade de São Paulo, São Paulo, 2003.

BRUNI, Lugino. Rumo a uma nova racionalidade econômica capaz de comunhão. In: __ (Org.). Economia de comunhão. São Paulo: Cidade Nova, 2002. 2005.

. Comunhão e as novas palavras da economia. São Paulo: Cidade Nova,

BURREL, G.; MORGAN, G. Sociological paradigms and organizational analysis. London: Heineman, 1979.

CARVALHO, P. R. P. Organizações de aprendizagem: uma exploração multidisciplinar sobre obstáculos a sua implementação. 1999. Dissertação (Mestrado) — Departamento de Administração da PUC-Rio, Rio de Janeiro, 1999.

DALABRIDA, Ivan. Novas formas de atualização empresarial na construção do desenvolvimento sustentável. 2004. Dissertação (Mestrado) — Departamento de Administração de Empresas e Desenvolvimento Sustentável, Universidade Regional de Blumenau, SC, 2004.

ENRIQUEZ, Eugène. Os desafios éticos nas organizações modernas. Revista de Administração de Empresas, v. 37, n. 2, p. 6-17, abr./jun. 1997.

FERREIRA, Sandra R. Carisma e modernidade: Ginetta Calliari, "a ética e o espírito da economia de comunhão". Dissertação (Mestrado) — Universidade de São Paulo, 2004.

FORTES, R. L. F. A centralidade do homem no comportamento organizacional das empresas de economia de comunhão. 2004. Monografia (Especialização em Gestão Competitiva Empresarial) — Universidade Federal do Piauí, Brasil. 
GAMELEIRA, C. S. L. A solidariedade como fundamento do desenvolvimento local sustentável do município alagoano de Branquinhos. 2000. Dissertação (Mestrado) - Programa Regional de Pós-Graduação em Desenvolvimento e Meio Ambiente da Universidade Federal de Alagoas, 2000.

GONÇALVES, H. H. A. B. Q. A experiência dos pioneiros da economia de comunhão na liberdade no primeiro decênio (1991-2001) no Brasil: absurdo e graça da mudança de mentalidade do empresário. 2005. Tese (Doutorado) - Coppe/UFRJ, Rio de Janeiro, 2005.

; LEITÃO, S. P. Empresas de economia de comunhão: o caso Femaq. Revista de Administração Pública, v. 35, n. 6, p. 33-60, nov./dez. 2001.

KURTZ, R. G. M. Relacionamentos interpessoais e aprendizagem organizacional na economia de comunhão. 2005. Dissertação (Mestrado) — Departamento de Administração da PUC-Rio, Rio de Janeiro, 2005.

LEITÃO, S. P.; LAMEIRA, V. J. Humanismo e mudança organizacional. Revista de Administração Pública, v. 39, n. 3, p. 703-730, maio/jun. 2005.

LEITE, K. C. Economia de comunhão: uma mudança cultural e política na construção do princípio da reciprocidade nas relações econômicas. 2005. Tese (Doutorado) - Programa de Pós-Graduação em Ciências Sociais da Universidade Federal de São Carlos, São Paulo, 2005.

LIMA JR., Benedit. A importância do lucro nas empresas de economia de comunhão. 2006. Dissertação (Mestrado) - Faculdade de Administração da Universidade Paulista, São Paulo, 2006.

LIMA, M. A. B. Economia de comunhão X custos de transação: uma visão das organizações imbuídas da cultura da partilha. Revista Eletrônica de Administração, 12. ed., v. 5, n. 4, nov./dez. 1999.

LINARD, Keith T. Economy of communion: sistemic factors in the rise of a new entrepreneurship. Systems Research and Behavioral Science, n. 20, p. 163-175, 2003. Disponível em: <www.interscience.wiley.com>.

LINCOLN, Y.; GUBA, E. G. Paradigmatic controversies, contradictions and emerging confluences. In: DENZIN, N. K.; LINCOLN. (Eds.). Handbook of qualitative research. London: Sage, 2000.

LUBICH, Chiara. Economia de comunhão, história e profecia. São Paulo: Cidade Nova, 2004.

MACHADO, A. C. M. Economia de comunhão: elementos para uma teoria organizacional. 2006. Tese (Doutorado) - Departamento de Engenharia Industrial da PUC-Rio, Rio de Janeiro, 2006. 
MEDAGLIA, A. B. Aspectos éticos de projeto de economia de comunhão: uma alternativa na administração de empresas. 2003. Dissertação (Mestrado) — Universidade de Marília, Paraná, 2003.

MENDES, N. D. Relações interpessoais: um estudo de caso das empresas de EdC. 2003. Dissertação (Mestrado em Administração) — Universidade Federal da Paraíba, 2003.

MERLA, L. La responsailitá sociali delle aziende aderentti ao projetto "Economia di Comunione". 2003. Tese (Láurea in Economia i Comecio) — Universitá Degli Studi di Bergamo, Facolta di Economia, Itália, 2003.

NASCIMENTO, A. A. S. Produtividade e humanização do lucro: economia de comunhão. 1999. Dissertação (Mestrado) — Programa de Pós-Graduação em Administração da PUC-SP, São Paulo, 1999.

OLIVEIRA, Rosiska. Reengenharia do tempo. Rio de Janeiro: Rocco, 2003.

PINTO, M. C. S. A economia de comunhão sob o olhar da teoria dos stakeholders. 2004. Tese (Doutorado) - Departamento de Administração da PUC-Rio, Rio de Janeiro, 2004.

; LEITÃO, S. P. Economia de comunhão, empresas para um capitalismo transformado. Rio de Janeiro: FGV, 2006.

SAMPAIO, M. A. L. Economia de comunhão e o conceito de organização de aprendizagem. 2006. Dissertação (Mestrado) — Departamento de Administração da PUC-RJ, Rio de Janeiro, 2006.

SANTANA, S. C. Princípios para um modelo de gestão ambiental sobre o duplo enfoque de tecnologias limpas e economia de comunhão. 2003. Dissertação (Mestrado) - Programa de Pós-Graduação em Desenvolvimento e Meio Ambiente da Universidade Federal de Sergipe, 2003.

SERAFIM, M. C. A ética no espaço de produção: contribuições da economia de comunhão. 2001. Dissertação (Mestrado) — Universidade do Extremo Sul Catarinense, SC, 2001.

SILVEIRA, C. N. Relações entre responsabilidade social e economia de comunhão: um estudo de caso com empresas do pólo Spartaco. 2003. Dissertação (Mestrado) - Centro Universitário Moura Lacerda, 2003.

SPERS, V. R. E. Organização e economia de comunhão: relações sociais e subjetivas permeadas pela religiosidade? 2004. Tese (Doutorado) — Programa de Pós-Graduação em Ciências Sociais da PUC-SP, São Paulo, 2004. 
VIDO, Eloi. Gestão baseada em princípios de EdC: uma proposta de mudança na cultura da empresa. 2004. Dissertação (Mestrado em Administração) — Universidade Mackenzie, São Paulo, 2004.

WELLEN, H. O "novo" aos olhos do "velho": uma leitura da economia de comunhão a partir do pensamento de Marx. 2004. Dissertação (Mestrado) — Programa de Pós-Graduação em Administração da Universidade Federal do Rio Grande do Norte, 2004.

ZAMAGNI, Stefano. Fundamento e significado da experiência de economia de comunhão. In: BRUNI, L. (Org.). Economia de comunhão. São Paulo: Cidade Nova, 2002. 